\title{
Editorial
}

\section{Microstrip Antennas: Future Trends and New Applications}

\author{
Hala A. Elsadek, ${ }^{1}$ Esmat A. Abdallah, ${ }^{1}$ Dalia M. Elsheakh, ${ }^{1}$ \\ and Heba Badr El-Din El-Shaarawy ${ }^{2}$ \\ ${ }^{1}$ Microstrip Department, Electronics Research Institute, National Research Center Buildings, Elthrir Street, Dokki, Giza 12622, Egypt \\ ${ }^{2}$ Micro and Nano Systems for Wireless Communications (MINC), Laboratoire d'Analyse et d'Architectures des Systems, \\ Centre National de la Recherche Scientifique (LAAS-CNRS), 75794 Paris, France
}

Correspondence should be addressed to Hala A. Elsadek; helsadek@mcit.gov.eg

Received 14 February 2013; Accepted 14 February 2013

Copyright (C) 2013 Hala A. Elsadek et al. This is an open access article distributed under the Creative Commons Attribution License, which permits unrestricted use, distribution, and reproduction in any medium, provided the original work is properly cited.

The explosive growth in the demand for wireless communication and information transfer using handsets and personal communications (PCS) devices has created the need for major advancements of antenna designs as a fundamental part of any wireless system. One type of antennas that fulfills most of the wireless systems requirements is the microstrip antennas. These antennas are widely used on base stations as well as handheld devices. Microstrip antennas have a variety of configurations and are currently the most active field in antenna research and development. The microstrip antennas, due to their great advantages, have increasingly wide range of applications in wireless communication systems as handheld mobile devices, satellite communication systems, and biomedical applications. In most PCS, the handheld antenna is placed on a small plastic/shielding box that is in close proximity to biological tissue of user body hence its radiation may cause health hazardous effects. Added to the operational requirements, the users and service providers usually demand wireless units with antennas that are small and compact, cost effective for manufacturability, low profile, and easy to integrate with other wireless communication system components. The antenna designer must consider all these issues besides the electrical characteristics of the antenna performance which include antenna tuning (operating frequency), VSWR and return loss (input impedance), bandwidth, gain and directivity, radiation pattern, diversity, and size of the chassis (expressed as a function of wavelengths) and specific absorption rate (SAR) of the antenna. These design considerations have led antenna designers to consider a wide variety of structures to meet the often conflicting needs for different applications.

This special issue contains different topics about microstrip antennas. New designs are investigated for several wireless communication applications. Papers are classified from survey about most literature publications in several topics as RF energy harvesting to new designs in UWB antennas, reconfigurable antennas, smart MIMO systems, and so forth.

We hope the readers and researches of microstrip antenna systems will find in this special issue not only new designs about different microstrip antenna characteristics but also valuable information about numerical analysis and fabrications.

Hala A. Elsadek

Esmat A. Abdallah

Dalia M. Elsheakh

Heba Badr El-Din El-Shaarawy 

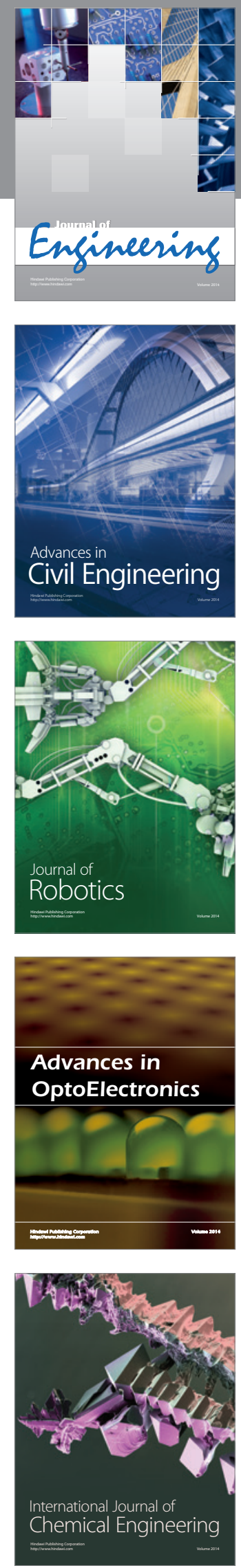

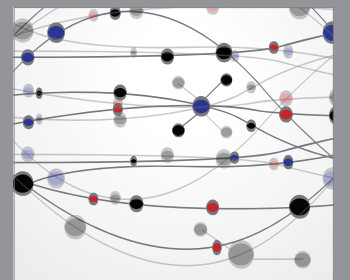

The Scientific World Journal
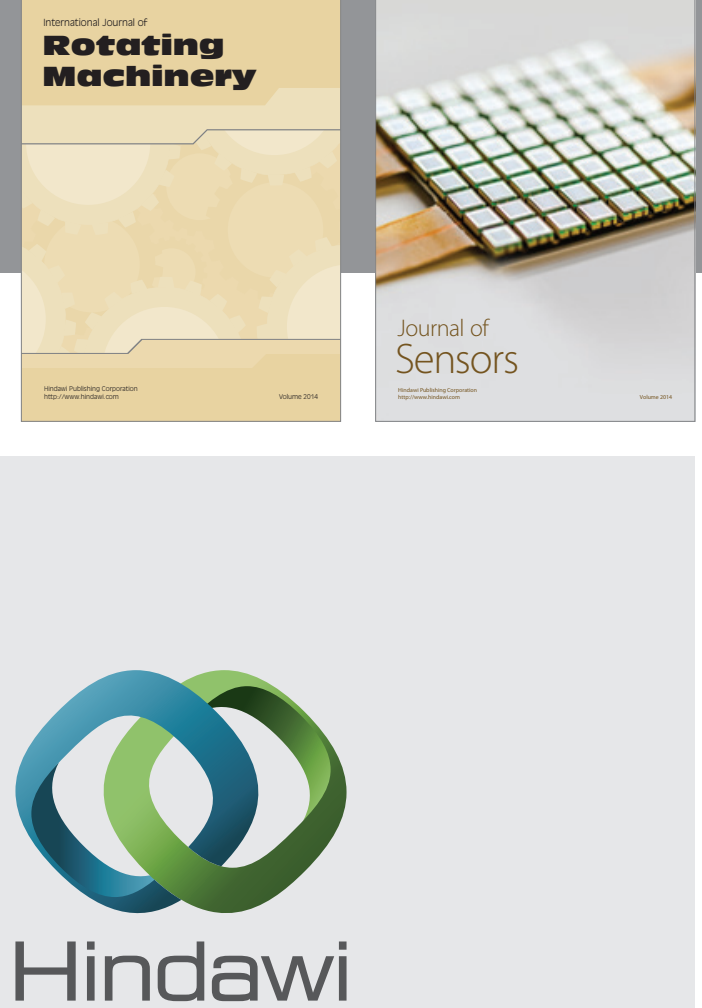

Submit your manuscripts at http://www.hindawi.com
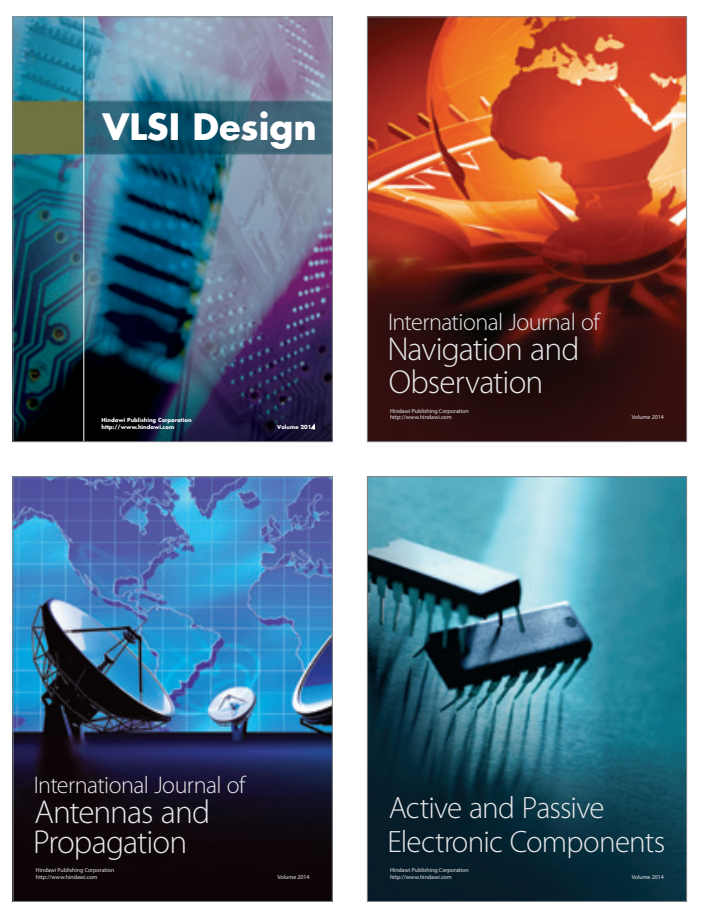
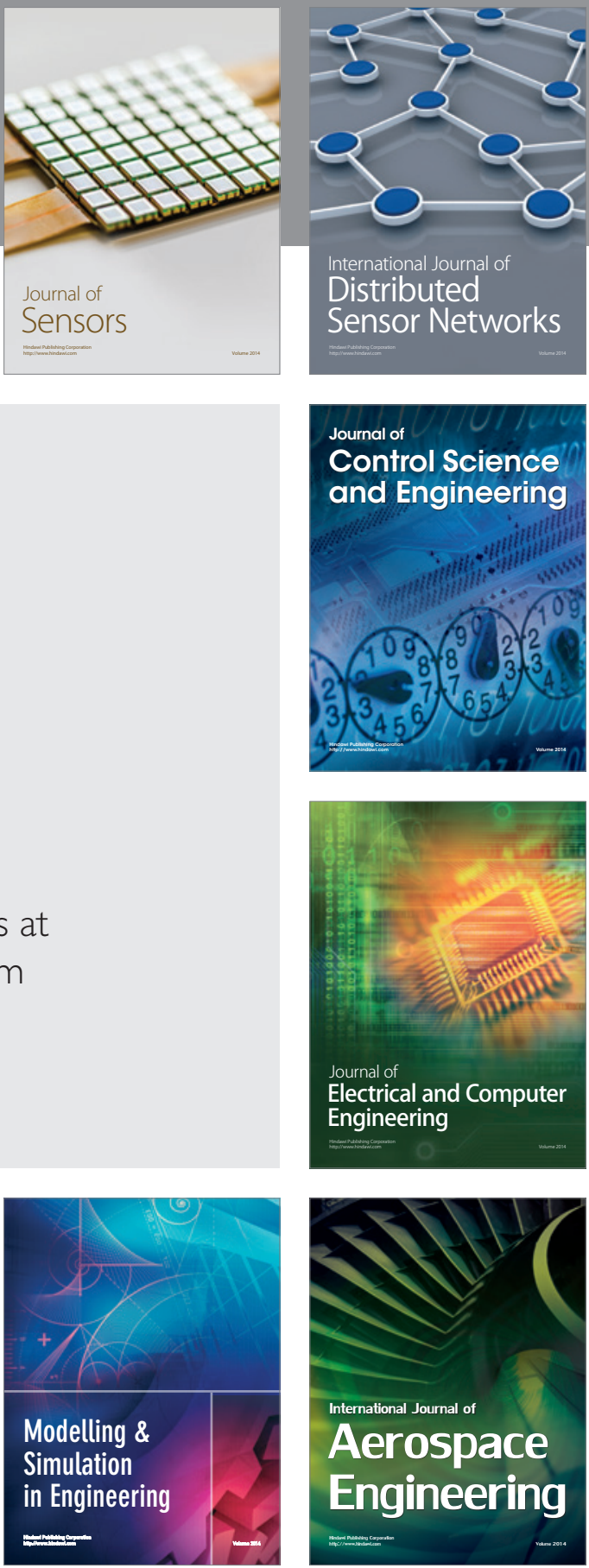

Journal of

Control Science

and Engineering
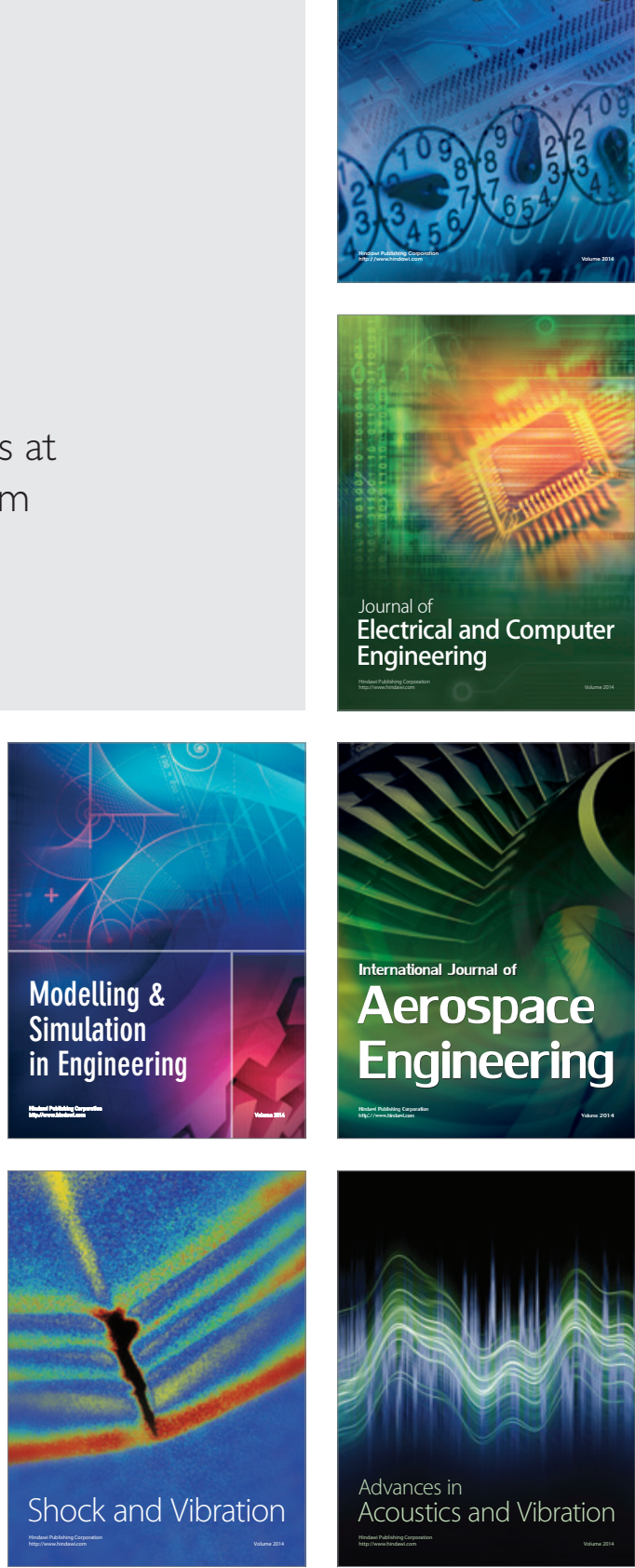